\title{
Nephroprotection of lacidipine against gentamycin-induced nephrotoxicity in albino rats
}

\author{
This article was published in the following Dove Press journal: \\ Journal of Experimental Pharmacology \\ 3 June 2010 \\ Number of times this article has been viewed
}

\section{Sahar Kamal \\ Pharmacology Department, Faculty of Medicine, Ain Shams University, Cairo}

Correspondence: Sahar Kamal Pharmacology Department, Faculty of Medicine, Ain Shams University, Cairo, Egypt

Tel +20224186992

$\mathrm{Fax}+20224186992$

Email saharkamal2003@hotmail.com
Aim: Gentamycin, a widely-used aminoglycoside antibiotic, is recognized as possessing significant nephrotoxic potential in human beings. Gentamycin-induced nephrotoxicity is suggested to be mediated via reactive oxygen species. The present study investigated the possible antioxidant nephroprotective effect of lacidipine as a calcium-channel blocker in a gentamycin-induced nephrotoxicity model in albino rats.

Methods: Albino rats were divided into 3 groups. Group 1 received normal saline. Group 2 received gentamycin $80 \mathrm{mg} / \mathrm{kg}$ intraperitoneally for 14 days. Group 3 received lacidipine $1 \mathrm{mg} / \mathrm{kg}$ intraperitoneally 3 days before and 14 days concurrently with gentamycin. This dose does not affect the blood pressure of rats, as evidenced in the pilot study.

Results: Gentamycin-induced nephrotoxicity was evidenced by a marked reduction in creatinine clearance. Treatment with lacidipine improved creatinine clearance compared to the gentamycin-treated group. In addition, it reduced thiobarbituric acid reactive substance, as an index of lipid peroxidation, with significant increases in superoxide dismutase enzyme in erythrocyte lysates and kidney catalase enzyme activities.

Conclusion: This study recommends the use of lacidipine in prophylaxis against gentamycininduced nephrotoxicity.

Keywords: lacidipine, gentamycin, nephrotoxicity, antioxidant, albino rats

\section{Introduction}

Antioxidants are defined as substances that, when present at a low concentration relative to an oxidizable substrate, significantly delay or prevent oxidation of that substrate. Antioxidant mechanisms can be divided into two major classes based on their mode of action: antioxidant enzymes and nonenzymatic antioxidants (scavengers). ${ }^{1}$ The class of antioxidant enzymes consists of superoxide dismutase (SOD), catalase, and glutathione peroxidase. Dismutation of oxygen free radicals by SOD produces hydrogen peroxide, a more stable reactive oxygen species (ROS) which, in turn, is converted to water by catalase and glutathione peroxidase. An antioxidant effect may result from either activation or mimicry of antioxidant defenses. Alternatively, it may be due to interaction with factors involved in the activation of oxidative stress. ${ }^{2}$

Gentamycin, being one of the aminoglycosides, is a very important agent for the treatment of Gram-negative bacterial infections. However, its clinical use is limited by its nephrotoxicity. ${ }^{3}$

Oxidative stress describes the injury caused to cells by the oxidizing of macromolecules resulting from increased formation of ROS and/or decreased antioxidant reserve. Oxidative stress contributes to vascular diseases by promoting 
vascular smooth muscle proliferation, monocyte/macrophage infiltration, vascular tone alteration, and matrix metalloproteinase activation. ${ }^{1}$

The antioxidant action of calcium-channel blockers (CCBs) has been demonstrated in some experimental setups. A study has reported that treatment of the endothelium with dihydropyridine calcium antagonists resulted in an increased release of nitrogen monoxide that is not due to a modulation of L-type calcium channels, because macrovascular endothelial cells do not express this channel. ${ }^{4}$ Increased nitrogen monoxide availability may cause part of the vasodilation, and might contribute to the antithrombotic, antiproliferative, and antiatherosclerotic effects of dihydropyridine calcium antagonists. $^{4}$

Therefore, the present study investigates, in the gentamycin-induced nephrotoxicity model, the effect of concomitant treatment with gentamycin and lacidipine, as a dihydropyridine $\mathrm{CCB}$, on creatinine clearance, and some oxidative markers, in kidney homogenates of albino rats.

\section{Methods}

\section{Drugs}

Lacidipine ester was provided as powder by GlaxoSmithKline, Philadelphia, PA, USA. Super oxide dismutase (RANSOD) was supplied by Randox Laboratories, Kearneysville, WV, USA. Gentamycin sulphate (salt) and all other chemicals were purchased from Sigma Chemicals, St Louis, MO, USA.

\section{Animals}

Thirty-six male albino rats weighing 180-200 g, were used in this study. They were randomly allocated into three groups of 12. Rats were housed in individual plastic cages and allowed one week to acclimate to their surroundings before the beginning of the experiments. Standard rat chow and tap water were available ad libitum for the duration of the experiments, unless otherwise noted.

\section{Ethics}

All procedures were in accordance with the National Institute of Health's Guide for the Care and Use of Laboratory Animals, as well as the guidelines of the Animal Welfare Act.

\section{Experimental protocol}

Albino rats were divided into three groups. Group 1 received normal saline intraperitoneally (ip). Group 2 received gentamycin dissolved in dimethylsulphoxide (DMSO) at a dose of $80 \mathrm{mg} / \mathrm{kg}$ ip for 14 days. Group 3 received lacidipine dissolved in $0.5 \%$ methylcellulose at a dose of $1 \mathrm{mg} / \mathrm{kg}$ ip 3 days before and 14 days concurrently with gentamycin. A pilot study determined that this does does not affect the blood pressure of albino rats.

In the pilot study, an experimental group $(n=12)$ received only $0.5 \%$ methylcellulose + gentamycin in DMSO to test it without the drug for a duration of 3 days before and 14 days concurrently with gentamycin. Results were similar to that obtained with Group 2. Our conclusion was that no difference was made by the solvent of the drug.

\section{Renal function}

Albino rats were individually housed in metabolic cages for 24 hours at the end of the study. During the 24 hour period, animals continued to have free access to tap water and standard laboratory rat chow. Urine volume per 24 hours was calculated for each animal. Serum and urine creatinine concentrations were measured using a Beckman ${ }^{\circledR}$ Analyzer (Beckman Coulter, Brea, CA, USA) according to the picric acid colorimetric method, ${ }^{5}$ and creatinine clearance in different groups was calculated using the following formula: ((urine creatinine $_{(\mathrm{mg} / \mathrm{dL})} \times$ urine volume per day $\left._{(\mathrm{mL})} \div 1440_{(\mathrm{min})}\right) \div$ serum creatinine $\left._{(\mathrm{mg} / \mathrm{dL})}\right) \div$ body weight $_{(\mathrm{g})} \times 100 .^{6}$

\section{Determination of SOD enzyme level in erythrocyte lysates}

At the end of the study, blood samples were collected from rats from all groups for measurement of SOD levels in erythrocyte lysates, using commercially-available colorimetric assay kits, based on an indirect xanthine-xanthine oxidase method, ${ }^{7}$ and results were expressed in $\mathrm{IU} / \mathrm{mL}$.

\section{Measurement of kidney thiobarbituric acid-reactive substances (TBARS) as a marker of lipid peroxidation}

Kidney homogenates were rinsed with cold $0.14 \mathrm{M}$ sodium chloride and homogenized in $25 \%$ ice-cold $50 \mathrm{mM}$ Tris-HCl buffer ( $\mathrm{pH} 7.4) .{ }^{8} 150 \mu \mathrm{L}$ of the tissue supernatant of samples were diluted to $500 \mu \mathrm{L}$ with deionized water. $250 \mu \mathrm{L}$ of $1.34 \%$ thiobarbituric acid was added to each tube, followed by the addition of an equal volume of $40 \%$ trichloroacetic acid. The mixtures were then shaken and incubated for 30 minutes in a boiling water bath. Tubes were allowed to cool to room temperature, and the absorbance was then read at $532 \mathrm{~nm}$, using zero concentration as blank. ${ }^{8}$ 


\section{Catalase enzyme activity in kidney homogenates}

Parts of kidney homogenates of different groups were homogenized in $1 \%$ Triton ${ }^{\circledR} \mathrm{X}-100$ in the assay buffer at about $20,000 \times \mathrm{g}$ for 30 seconds on ice. The homogenates were centrifuged at $6000 \times \mathrm{g}$ at $4^{\circ} \mathrm{C}$ for 20 minutes. The supernatant was diluted with 1.5 volumes of the assay buffer ( $50 \mathrm{mM} \mathrm{KH} \mathrm{PO}_{4} / 50 \mathrm{mM} \mathrm{Na} \mathrm{HPO}_{4}$ at $\mathrm{pH} 7.0$ ). The enzyme activity was determined by the method described by Aebi. ${ }^{9}$ Briefly, in a $5 \mathrm{~mL}$ cuvette, $2 \mathrm{~mL}$ of sample were added, and the reaction was initiated by adding $1 \mathrm{~mL} 30 \mathrm{mM}$ $\mathrm{H}_{2} \mathrm{O}_{2}$, and the change in absorbance at $240 \mathrm{~nm}$ was monitored at $25^{\circ} \mathrm{C}$ for one minute. A portion of the remaining sample was used for protein determination. Specific activity is expressed as $\mu \mathrm{M} \mathrm{H}_{2} \mathrm{O}_{2} / \mathrm{min} / \mathrm{mg}$ of protein.

\section{Protein determination}

The protein content of kidney homogenates was determined by spectrophotometer according to the method of Bradford. ${ }^{10}$ The aim is to relate the oxidative marker concentrations to the total tissue protein.

\section{Statistical analysis}

The results are presented as mean \pm standard deviation, and evaluated using one-way analysis of variance (ANOVA), followed by Bonferroni's post hoc determination, using GraphPad Prism (version 3.00; GraphPad Software, La Jolla, CA, USA).

\section{Results}

\section{Effect of lacidipine treatment on creatinine clearance in rats exposed to gentamycin-induced nephrotoxicity}

Figure 1 demonstrates an increase in creatinine clearance in rats treated with lacidipine concurrently with gentamycin. Creatinine clearance, in $\mathrm{mL} / \mathrm{min}$, of the different groups (saline, gentamycin, and gentamycin + lacidipine) was calculated. Compared with the control group, the gentamycin group was associated with a significant $(P<0.05)$ decrease in creatinine clearance. This decrease was significantly $(P<0.05)$ increased compared to gentamycin group.

\section{The mean \pm SD of lacidipine on SOD levels} in erythrocyte lysates

Exposure to the gentamycin-induced nephrotoxicity model showed a significant $(P<0.05)$ decrease in SOD in erythrocyte lysates compared to control group. Concomitant administration of lacidipine with gentamycin significantly

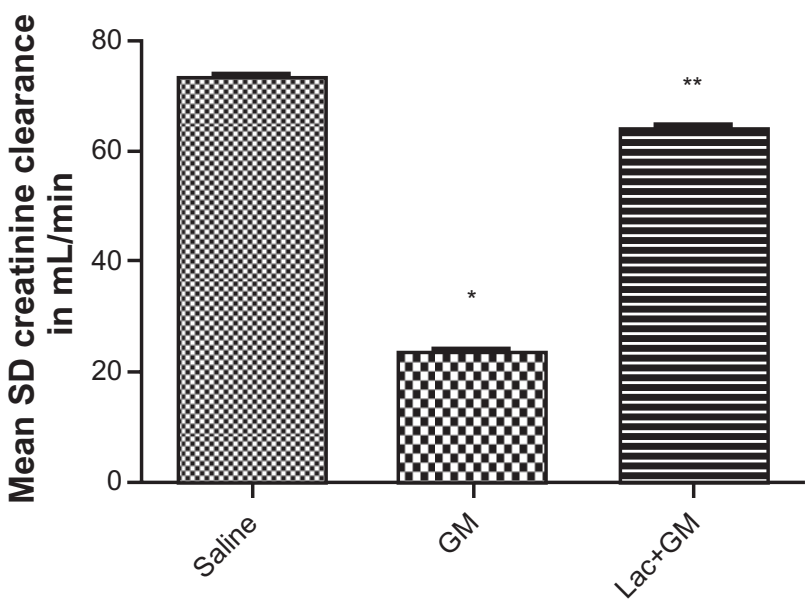

Figure I Improvement of creatinine clearance after intraperitoneal administration of lacidipine in albino rats treated with gentamycin.

Notes: ${ }^{*} P<0.05$ significant reduction in creatinine clearance compared to control group. ${ }^{* *} P<0.05$ significant increase in creatinine clearance compared to GM group. Abbreviations: SD, standard deviation; GM, gentamycin; Lac, lacidipine.

$(P<0.05)$ restored SOD levels compared to control levels (Table 1).

The mean \pm SD of lacidipine on TBARS and catalase enzyme activity in kidney homogenates

Kidney homogenates of the lacidipine-treated group showed significant $(P<0.05)$ restoration of TBARS to control levels, compared to the gentamycin-induced nephrotoxicity group. Catalase enzyme activity in the homogenates was significantly $(P<0.05)$ restored to control levels in the lacidipine-treated group compared to the significant $(P<0.05)$ decrease in its activity in the untreated gentamycin-induced nephrotoxicity group (Tables 1 and 2).

\section{Discussion}

The current study was undertaken to determine whether lacidipine administered to rats with gentamycin-induced nephrotoxicity can protect against oxidative stress, and can produce a beneficial effect on creatinine clearance compared with rats without lacidipine treatment.

The increase in TBARS production may contribute to impaired kidney function. Oxidative stress causes hypertrophy of nephrons via increased production of angiotensin II (AII), mediated by ROS..$^{11,12} \mathrm{AII}$ is a powerful stimulator of endothelin-1 (ET-1) release by cultured vascular smooth muscle and endothelial cells. ${ }^{13}$ Vascular ET-1 acts as an amplifier of the vasoconstrictor and proliferative effects of AII. ${ }^{14}$

More interestingly, increased tubular ET-1 synthesis, reported in oxidative stress, may induce fibroblast proliferation, interstitial matrix deposition, and infiltration of inflammatory 
Table I Effect of lacidipine on TBARS (in nmoL/mg tissue protein) and catalase enzyme activity (in $\mu \mathrm{moL} / \mathrm{min} / \mathrm{mg}$ tissue protein) in kidney homogenates

\begin{tabular}{lll}
\hline Substance & Control & $\begin{array}{l}\text { GM-induced nephrotoxicity } \\
\text { without lacidipine }\end{array}$ \\
\hline TBARS in nmoL/mg tissue protein & $0.74 \pm 0.2$ & $10.05 \pm 1.2^{*}$ \\
Catalase enzyme activity in & $112.6 \pm 10.52$ & $1.12 \pm 0.5^{*}$ \\
$\mu \mathrm{moL} / \mathrm{min} / \mathrm{mg}$ tissue protein & & $87 \pm 1 . \mathrm{I}^{*} \pm .2^{* *}$ \\
\hline
\end{tabular}

Notes: The results are expressed as means \pm standard deviation $(n=12$ in each group). The lacidipine-treated group significantly $(P<0.05)$ increased catalase enzyme activity, while there is significant $(P<0.05)$ reduction in TBARS in comparison to the untreated, GM-alone group. ${ }^{*} P<0.05$ significant increase in TBARS and significant decrease in catalase enzyme activity compared to the control group. ${ }^{* *} P<0.05$ significant decrease in TBARS and significant increase in catalase enzyme activity compared to untreated, GM-alone group.

Abbreviations: GM, gentamycin; TBARS, thiobarbituric acid-reactive substances.

cells - features typical of progressive tubulointerstitial fibrosis. Therefore, it seems that inhibition of oxidative stress can significantly retard the progression of renal and vascular complications. ${ }^{15}$

The antioxidant properties of CCBs are described as being due to either a direct scavenging effect or the preservation of SOD activity. Observations reported in the present study indicate that $\mathrm{CCBs}$ may also act by reducing the production of angiotensin and endothelin. Under controlled experimental conditions, they may inhibit lipid peroxide formation at concentrations present in plasma. This antioxidant activity is found with high lipophilic CCBs when their chemical structure facilitates proton-donating and stabilization mechanisms that quench the free radical reaction. Inserted in a location in the membrane near polyunsaturated fatty acids at relatively high concentrations, dihydropyridines are capable of donating protons to lipid peroxide molecules, thereby blocking the peroxidation process. The remaining unpaired free electron associated with the CCB molecule can be stabilized in well-defined structures associated with the dihydropyridine ring. ${ }^{13}$

That lacidipine causes a decrease in aortic ET-1 expression might be related also to the protection by lacidipine against the renal ischemic alterations caused by plasma renin activity (PRA) elevation. Prevention of PRA elevation by lacidipine would suppress excessive AII production by renin of

Table 2 Effect of lacidipine on the level of SOD (IU/ml) in RBCs lysate

\begin{tabular}{llll}
\hline Substance & Control & $\begin{array}{l}\text { GM-induced } \\
\text { nephrotoxicity } \\
\text { without lacidipine }\end{array}$ & GM + lacidipine \\
\hline $33.54 \pm 0.13$ & $11.89 \pm 2.66^{*}$ & $99.33 \pm 2.25^{* *}$ \\
\hline
\end{tabular}

Notes: The results are expressed as means \pm standard deviation $(n=12$ in each group). The lacidipine-treated group significantly $(P<0.05)$ increased SOD level, while there is significant $(P<0.05)$ reduction in its level in the untreated, GM-alone group. ${ }^{*} P<0.05$ significant decrease in SOD level compared to the control group. ${ }^{*} \mathrm{P}<0.05$ significant increase in SOD level compared to untreated, GM-alone group. kidney origin, thereby opposing AII-stimulated ET-1 gene overexpression in renal cells. ${ }^{16,17}$

Experimental research has explained the mechanism of GM-induced nephrotoxicity in the form of induction of renal oxidative stress by gentamycin, as shown by a reduction in kidney glutathione, and an increase in lipid peroxidation. ${ }^{18,19}$ Oxidative stress and nephrotoxicity are demonstrated in many experimental animal models. Lipoic acid significantly reduces the nephrotoxic symptoms produced by adriamycin, as evidenced by Malarlodi, Balachandar, and Varalakshmi. ${ }^{20}$ Some investigators demonstrated that lacidipine protected animals from cyclosporine-induced nephrotoxicity via its antioxidant properties. ${ }^{21}$ Lacidipine could act not only through renal protection against oxidative stress but also by interfering directly with the vascular and proliferative pathways activated by AII in the renal vessel wall. ${ }^{22,23}$ However, more research is recommended in order to prove this hypothesis.

\section{Conclusion}

In conclusion, the long-acting CCB lacidipine could protect albino rats against the impairment of kidney function evoked by gentamycin, and this may contribute to the beneficial effect against end-organ damage and oxidative stress reported in clinical trials. Further investigations on long-acting dihydropyridines are needed to discover their beneficial role in renal diseases.

\section{Acknowledgments}

This research was officially supported by the Medical Research Service of the Ain Shams University. It was financially supported by the laboratory of the Pharmacology Department, Faculty of Medicine, Ain Shams University.

\section{Disclosure}

The author reports no conflicts of interest in this work.

\section{References}

1. Zalba G, San Jose G, Moreno M, et al. Oxidative stress in arterial hypertension: role of NAD(P)H oxidase. Hypertension. 2001;38:1395. 
2. Sato J, O'Brien T, Katusic Z, Fu A, Nygren J, Singh R, Nair K. Dietary antioxidants preserve endothelium dependent vasorelaxation in overfed rats. Atherosclerosis. 2002;161:327-333.

3. Maldonado P, Barrera D, Medina-Campos O, Hernandez-Pando Ribarra-Rubio M, Pedraza-Chaverri J. Aged garlic extract attenuates gentamycin induced renal damage and oxidative stress in rats. Life Sci. 2003;73(20):2543-2556

4. Berkels R, Egink G, Marsen T, Bartels H, Roesen R, Klaus W. Nifedipine increases endothelial nitric oxide bioavailability by antioxidative mechanisms. Hypertension. 2001;37:240-245.

5. Wallach J. Interpretation Of Diagnostic Tests: A Handbook Synopsis of Laboratory Medicine. 3rd ed. Boston, MA: Little Brown; 1978.

6. Lu J, Bankovic-Calic N, Ogborn M, Saboorian M, Aukema H. Detrimental effects of a high fat diet in early renal injury are ameliorated by fish oil in Han:SPRD-cy Rats. J Nutr. 2003;133:180-186.

7. Halliwell B, Chirico S. Lipid peroxidation: its mechanism, measurement, and significance. Am J Clin Nutr. 1993;57:715S-725S.

8. Gutteridge J, Quinlan G: Malondialdehyde formation from lipid peroxides in the thiobarbituric acid test: the role of lipid radicals, iron salt and metal chelators. J Appl Biochem. 1983;5(4-5):293-299.

9. Aebi H. Catalase in vitro. Methods Enzymol. 1984;105:121-126.

10. Bradford M. A rapid and sensitive method for the quantitation of microgram quantities of protein utilizing the principle of protein-dye ninding. Anal Biochem. 1976;72:248-254.

11. Nakazono K, Watanabe N, Matsuno K, Sasaki J, Sato T, Inoue M. Does superoxide underlie the pathogenesis of hypertension?. Proc Natl Acad Sci U S A. 1991;88(22):10045-10048.

12. Hwang J, Ing M, Salazar A, et al. Pulsatile versus oscillatory shear stress regulates NADPH oxidase subunit expression: implication for native LDL oxidation. Circ Res. 2003;93:1225-1232.

13. Muller D, Mervaala E, Schmidt F, et al. Effect of bosentan on NF-KB, inflammation, and tissue factor in angiotensin II-induced end-organ damage. Hypertension. 2000;36:282.
14. Wilkinson-Berka J, Kelly D, et al. ALT-946 and aminoguanidine, inhibitors of advanced glycation, improve severe nephropathy in the diabetic transgenic (mREN-2)27 rat. Diabetes. 2002;51:3283-3289.

15. Orth S, Esslinger J, Amann K, Schwarz U, Raschack M, Ritz E. Nephroprotection of an $\mathrm{ET}_{\mathrm{A}}$-receptor blocker (LU 135252) in saltloaded uninephrectomized stroke-prone spontaneously hypertensive rats. Hypertension. 1998;31:995-1001.

16. Mason R. Mechanisms of plaque stabilization for the dihydropyridine calcium channel blocker amlodipine: review of the evidence. Atherosclerosis. 2002;165:191-199.

17. Kubo T, Saito E, Hosokawa H, Ibusuki T, Kambe T, Fukumori R. Local renin-angiotensin system and mitogen-activated protein kinase activation in rat aorta. Eur J Pharmacol. 1999;365:103-110.

18. Maldonado P, Barrera D, Madina-Campos O, Hernandez-Pando R, Ibarra-Rubio M, Pedraza-Chaverri J. Aged garlic extract attenuates gentamycin induced renal damage and oxidative stress. Life Sci. 2003;20:2543-2556

19. Mohamadin A, Abdou S, El-Shafey M, El-Tawil O, Moneir S. Protective effect of inosine against gentamycin induced oxidative stress and nephrotoxicity in rats. $J$ Biol Ph Sci. 2003;1:24-37.

20. Malarlodi K, Balachandar A, Varalakshmi P. The influence of lipoic acid on adriamycin induced nephrotoxicity in rats. Mol Cell Biochem $2003 ; 247(1-2): 15-22$.

21. Naidu M, Vijay-Kumar K, Anwar S, Prayag K. Lacidipine protects against cyclosporine induced nephrotoxicity in rats. Nephron. 1999;81:60-66.

22. Krenek P, Salomone S, Kyselovic J, Wibo M, Morel N, Godfraind T. Lacidipine prevents endothelial dysfunction in salt-loaded stroke-prone hypertensive rats. Hypertension. 2001;37:1124.

23. Sharifi A, He G, Touyz R, Schiffrin E. Vascular endothelin-1 expression and effect of an endothelin $\mathrm{ET}_{\mathrm{A}}$ antagonist on structure and function of small arteries from stroke-prone spontaneously hypertensive rats. J Cardiovasc Pharmacol. 1998;31:11-14.
Journal of Experimental Pharmacology

\section{Publish your work in this journal}

The Journal of Experimental Pharmacology is an international, peerreviewed, open access journal publishing original research, reports, reviews and commentaries on all areas of laboratory and experimental pharmacology. The manuscript management system is completely online and includes a very quick and fair peer-review system.

\section{Dovepress}

Visit http://www.dovepress.com/testimonials.php to read real quotes from published authors. 